\title{
Better Reporting and Awareness Campaigns Needed for Breast Cancer in Pakistani Women
}

This article was published in the following Dove Press journal:

Cancer Management and Research

\author{
Nazeer Hussain Khan (D) ${ }^{1,2}$ \\ Shao-Feng Duan ${ }^{3}$ \\ Dong-Dong $\mathrm{Wu} \mathbb{D}^{1,4}$ \\ Xin-Ying Ji $(\mathbb{D})^{1,4,5}$ \\ 'Henan International Joint Laboratory for \\ Nuclear Protein Regulation, Henan \\ University, Kaifeng, Henan, 475004, \\ People's Republic of China; ${ }^{2}$ School of \\ Life Sciences, Henan University, Kaifeng, \\ Henan, 475004, People's Republic of \\ China; ${ }^{3}$ Institute for Innovative Drug \\ Design and Evaluation, School of \\ Pharmacy, Henan University, Kaifeng, \\ Henan, 475004, People's Republic of \\ China; ${ }^{4}$ School of Basic Medical Sciences, \\ Henan University College of Medicine, \\ Kaifeng, Henan, 475004, People's \\ Republic of China; ${ }^{5}$ Kaifeng Key \\ Laboratory of Infection and Biological \\ Safety, Henan University College of \\ Medicine, Kaifeng, Henan, 475004, \\ People's Republic of China
}

\begin{abstract}
Breast cancer is the most commonly diagnosed cancer and the leading cause of cancer deaths in women globally. In 2018, 2.1 million new cases were reported, with 627,000 deaths. Pakistan has the highest incidence rate of breast cancer among Asian countries: one in every nine women has a lifetime risk of being diagnosed with breast cancer. By reason of many misconceptions about the etiology of the disease and socioeconomic factors, Pakistani women have very low rates of early detection and diagnose breast cancer at advance stages with fewer chances of survival. The key to cure the breast cancer is early diagnosis. The aim of current review is to highlight the factors leading to the delays in early presentation of breast cancer in Pakistani women and to summarize possible recommendations for educating women about early diagnosis along with palliative care facilities for patients suffering from breast cancer. Furthermore, this study appeals to both the general public and government in the belief that better reporting and awareness campaigns may bring more women to clinics for early diagnosis.
\end{abstract}

Keywords: breast cancer, health budget, Pakistani women, better reporting; awareness campaigns

\section{Breast Cancer in Pakistan}

Breast cancer is the most commonly diagnosed cancer and the leading cause of cancer deaths in women globally. In 2018, 2.1 million new cases were reported, with 627,000 deaths. ${ }^{1,2}$ Pakistan has the highest incidence of breast cancer among Asian countries: one in nine women is at risk of being diagnosed with breast cancer during their lifetime. ${ }^{3}$ According to the International Agency of Research on Cancer 2018 report, 34,066 new cases of breast cancer had been reported in Pakistani women. ${ }^{4}$ Unfortunately, coupled with delayed referral to appropriate facilities and late diagnosis in the country, mortality rate of breast cancer patients is high. ${ }^{5}$ The key to cure cancer is early diagnosis as concluded in different studies; if one is diagnosed at an early stage, there are greater chances of recovery and survival and diagnosis at later stages lowers the chances of survival, thus, it emphasises to spread awarness about the early diagnosis and treatment of breast cancer among the general public. ${ }^{6,7}$

\section{Causes of Breast Cancer}

There are several factors in the emergence of breast cancer that cause mutation and abnormal amplification of both oncogenes and antioncogenes of the human genome. The published literature has proved that the breast cancer incidence is highly related to
Xin-Ying Ji

Email ddwubiomed2010@163.com;

10190096@vip.henu.edu.cn

Cancer Management and Research 2021:13 2125-2129 
increasing age and recommended mammography screening at regular intervals. Besides age, other factors like family history, reproductive and estrogen factors, modern lifestyles with excessive alcohol consumption contribute prominently to breast cancer. ${ }^{8}$ Lack of resources for advanced research, expert oncologists and absence of proper reporting about the incidence of cases are the reasons that have kept the evaluation of risk factors for breast cancer in Pakistani women still on way. There are very few studies that have evaluated the risk factors behind the high burden of breast cancer in the country. Genetic testing in one of the largest studies on breast cancer in Pakistani women so far revealed that $B R C A 1 / B R C A 2$ mutations contribute in early onset of breast cancer. ${ }^{9}$ The limitation of resource is the main stumbling block for Pakistani reseachers to evaluate the errors in genes functions and further explorations on breast cancer prevalence in Pakistan.

In terms of diet and lifestyle, findings show that severe vitamin D deficiency in Pakistani women may contribute in the development of breast cancer. ${ }^{10}$ Additionally, it has been reported that, due to the lack of checks and balances of personal care cosmetics in Pakistan, there are dozens of easily available cheap and unregistered local hair-dye brands including those containing paraphenylenediamine, which contains high paraben content involved in mediating the breast cancer, thus contributing to the breast cancer incidence. ${ }^{11}$ Various risk factors, including age, body-mass index, marital status, parity, oral contraceptives, breastfeeding, smoking, physical activity, and menopausal status, are significantly associated with the increased risk of developing breast cancer in Pakistani women. ${ }^{12}$ Although there is scarcity of data, a study has revealed the connections of consanguinity (genetic relatedness) with risk of breast cancer in Pakistani females. ${ }^{13}$

\section{Delay in Early Diagnosis}

Delay in early detection of breast cancer diagnosis in women is a result of both patient and system level factors in many middle-income countries like Pakistan. ${ }^{14}$ These factors contribute to delay in women seeking help following the discovery of unusual breast symptoms, as well as the time to diagnosis and start of treatment once she got diagnosed. ${ }^{15}$ Due to the low health literacy, delay in the detection of early breast cancer, is a serious growing concern for Pakistani women. There is a dearth of comprehensive school level knowledge about breast cancer for girls to address the prevailing myths and misconceptions in the society related to breast cancer. ${ }^{16}$ Figure 1 depicts risk factors that lead to

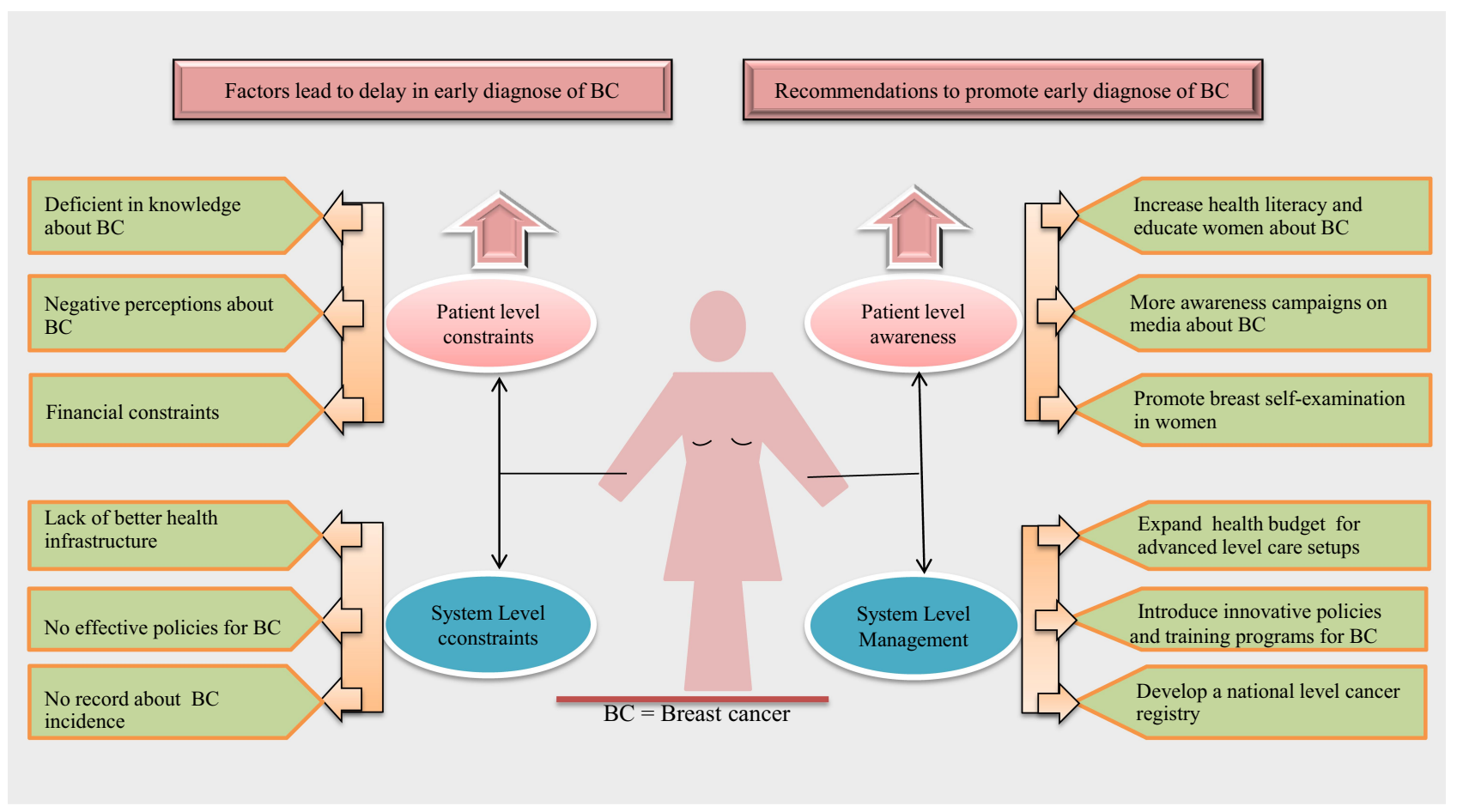

Figure I Diagram of risk factors that lead to delay in early diagnosis of breast cancer in Pakistani women and recommendations to overcome these factors. There are both patient-level socioeconomic constraints and lack of advanced medical facilities in Pakistan's health system holding back more women going to clinics for breast screening. Recommendations to address these factors include expanding the health budget and more awareness about breast cancer etiology with health education. 
the delay in early diagnosis of breast cancer in Pakistani women and recommendations to overcome these factors.

\section{Patient Socioeconomic Constraints}

Pakistani women lack the knowledge about breast cancer etiology, leading to the high prevalence. ${ }^{17}$ There is still an imperative need to change negative sociocultural perceptions of cancer, where women believe that cancerous cells will spread to the unborn child, conceal breast lumps from family members, and refer to religious peers for spiritual advice and support. ${ }^{18}$ Lack of knowledge about breast cancer, socioeconomic status, and lack of advanced medical facilities are potential factors in holding back the breast cancer diagnosis a decade earlier in Pakistani women as compared to Western women. ${ }^{19}$ Women consider the breast as a secret organ, and are more likely to avoid being seen by male doctors. ${ }^{19,20}$ According to a recent study, $40.7 \%$ of Pakistani women wasted their time using alternative medicines, $17.1 \%$ ignored painless lumps and $10.6 \%$ presented late because they considered the breast a secret organ. ${ }^{21}$ Aside from cancer awareness and cultural issues, a majority of patients, especially from rural areas, report late because of financial constraints or they believe that treatment will be unaffordable for them. ${ }^{20,22-24}$

\section{System-Level Factors}

Access to care is a challenge in many countries with limited resources. In Pakistan, total health expenditure is only $2.6 \%$ of gross domestic product, and the facilities for cancer diagnosis and management are very limited in hospitals. Annually, 175,000 people diagnosed with cancer and impose further extensive social and economic strain on an already struggling health system. ${ }^{25}$ Cancer care in Pakistan is not developed yet. There are still a lot of restrictions in terms of both trained manpower and infrastructure. National policy about health lacked effective training programs and patients to physician ratio is high. ${ }^{26}$ Presently, apart from a few cancer centers, government hospitals face a shortage of adequate medical facilities like mammography, supply of oncologists and nursing specialists as well. ${ }^{27}$ Furthermore, country also lacks no comprehensive registries/databases to document breast cancer death rates, accurate annual occurrence or the number of new cases regarding early management. ${ }^{28}$ Although Pakistan has charity hospitals like Shaukat Khanum Cancer Hospital and many non-government organizations to support poor cancer patients, but low awareness and knowledge about walk-in clinics, majority of patients struggle with health-care needs at local-level care facilities. It may yet take time for a uniform referral system to operate in the country, but what can be easily done is the provision of access to the latest guidelines and procedures at the local level to the local community.

\section{Recommendations}

In order to address the urgency of breast cancer, Pakisan is in dire need to initiate multi-pronged strategies, including better reporting and documentation of cases, communitylevel awareness, promoting the early detection of breast cancer, overcoming the barriers in the provision of better health facilities and making diagnosis easy.

\section{Awareness and Health Literacy}

As stated earlier, Pakistani women are deficient in knowledge about breast cancer. Breast cancer awareness includes addressing misapprehensions about the subject and prioritizing healthy lifestyle adjustments. Pakistan needs broaderlevel efforts to educate women about the etiology of cancer, breast self-examination and mammographic screening.

To make knowledge of breast cancer more widespread among Pakistani women, it should be ensured that all Pakistanis are educated in the fact that cancer is not a communicable disease or one that is transmitted by personal contact. There is an urgent need to start culturally sensitive educative programs about women's health, especially breast cancer and its risk factors related to environmental and lifestyle factors at the community level with primary care.

To promote the education in women, concern institutes need to launch massive awareness campaigns on both electronic and print media to break all sociocultural stigmas and urge the women to walk in near by clinics for breast examination.

To address cultural, religious and other social beliefs related to the subject, educational material must be customized to promote early breast examinations in women in case of any signs and symptoms. Clinical breast examination is a viable option to downstage tumors and mitigate the mortality. It all demands the adoptation of multipleintegrated measurements to set trends of early presentation and breast self-examination in women.

\section{Affordable and Accessible Care}

The health-care system of Pakistan is in dire need of occurrence because this will fill the gap in the lack of advanced equipped infrastructure and trained staff to 
high patient-physician ratio. The provision of affordable and accessible facilities for early detection and treatment may lead to earlier breast examinations in women.

For better management and effective planned polices, there is an urgent need to set up a national-level cancer-registry database that can provide accurate prevalence of diagnosed cases, survival rates, and other related parameters.

The government must invest in cost-effective early breast cancer-detection strategies to promote down staging and ensure the availability of accessible specialized hospitals for breast cancer, trained female oncologists, nursing staff, genetic counseling centers and awareness chapters in course books.

\section{Conclusion}

In conclusion, the available evidence on breast cancer incidence in women reveal that, in Pakistan, only few centers provide early and multimodality protocol-based treatments for breast cancer, thus, a majority of the patients with breast cancer attain inadequate treatments. Due to low health budget of the country, there is a scarcity of modern cancer care infrastructure. It also shows that Pakistani women are deficient in knowledge about breast cancer and follow many prevalent superstitions and spiritual statements about the disease. This review highlights that there is an urgent need to educate the women, promote early diagnosis of breast cancer and ensure the better equipped public facilities for palliative care of patients suffering from breast cancer. We believe, with further inquiries addressing the delay factors in early diagnosis of breast cancer in Pakistan, awareness and an affordable, accessible health-care system will win the war against breast cancer in women and improve cancer survival rate in the country.

\section{Dedication}

NHK dedicates this paper to the memory of his father's sister, Kaneez Bibi, who was diagnosed with stage III breast cancer in June 2019 and died in January 2020, and to the gorgeous Pakistani actress Nadia Jameel, who was diagnosed with stage I breast cancer in April 2020 and recovered.

\section{Acknowledgment}

The authors pay thanks to the National Natural Science Foundation of China (81670088 and 81602708) for financial support. The authors would like to express their gratitude to the anonymous referees who helped to improve this paper. NHK is deeply thankful to Piayree Lala, whose presence gives him reason and strength for this contribution in science.

\section{Author Contributions}

All authors made substantial contributions to conception and design, acquisition of data, or analysis and interpretation of data, took part in drafting the article or revising it critically for important intellectual content, agreed to submit to the current journal, gave final approval to the version to be published, and agree to be accountable for all aspects of the work.

\section{Disclosure}

The authors hereby declare that they have no conflicts of interest to disclose.

\section{References}

1. Bray F, Ferlay J, Soerjomataram I, Siegel RL, Torre LA, Jemal A. Global cancer statistics 2018: GLOBOCAN estimates of incidence and mortality worldwide for 36 cancers in 185 countries. CA Cancer J Clin. 2018;68(6):394-424.

2. Fitzmaurice C, Allen C, Barber RM, et al. Global, regional, and national cancer incidence, mortality, years of life lost, years lived with disability, and disability-adjusted life-years for 32 cancer groups, 1990 to 2015: a systematic analysis for the global burden of disease study. JAMA Oncol. 2017;3(4):524-548. doi:10.1001/ jamaoncol.2016.5688

3. Sohail S, Alam SN Breast cancer in Pakistan-awareness and early detection; 2007.

4. Organization WH. The global cancer observatory. All cancers Source; 2019.

5. Begum N. Breast cancer in Pakistan: a looming epidemic. $J$ Coll Physicians Surg Pak. 2018;28(2):87-88. doi:10.29271/jcpsp.2018.02.87

6. Society AC. Breast cancer early detection and diagnosis; 2020. Available from: https://www.cancer.org/cancer/breast-cancer/screen ing-tests-and-early-detection.html. Accessed December 4, 2020.

7. Rivera-Franco MM, Leon-Rodriguez E. Delays in breast cancer detection and treatment in developing countries. Breast Cancer. 2018;12:1178223417752677.

8. Sun YS, Zhao Z, Yang ZN, et al. Risk factors and preventions of breast cancer. Int J Biol Sci. 2017;13(11):1387-1397. doi:10.7150/ijbs.21635

9. Rashid MU, Muhammad N, Naeemi H, et al. Spectrum and prevalence of BRCA1/2 germline mutations in Pakistani breast cancer patients: results from a large comprehensive study. Hered Cancer Clin Pract. 2019;17(1):27. doi:10.1186/s13053-019-0125-5

10. Shamsi U, Khan S, Azam I, et al. A multicenter case control study of association of vitamin D with breast cancer among women in Karachi, Pakistan. PLoS One. 2020;15(1):e0225402.

11. Ilyas F Chemically-laced mehndi in widespread use from. Dawn News; September 29, 2008. Available from: https://www.dawn.com/ news/919504/chemically-laced-mehndi-in-widespread-use. Accessed December 4, 2020.

12. Romieu II, Amadou A, Chajes V. The role of diet, physical activity, body fatness, and breastfeeding in breast cancer in young women: epidemiological evidence. Rev Invest Clín. 2017;69(4):193-203.

13. Liede A, Malik IA, Aziz Z, De Los Rios P, Kwan E, Narod SA. Contribution of BRCA1 and BRCA2 mutations to breast and ovarian cancer in Pakistan. Am J Hum Genet. 2002;71(3):595-606. doi:10. $1086 / 342506$ 
14. Caplan LS, Helzlsouer KJ. Delay in breast cancer: a review of the literature. Public Health Rev. 1992;20(3-4):187-214.

15. Scheel JR, Anderson S, Foerster M, Galukande M, McCormack V. Factors contributing to late-stage breast cancer presentation in sub-Saharan Africa. Curr Breast Cancer Rep. 2018;10(3):142-147. doi:10.1007/s12609-018-0278-7

16. Shamsi U, Khan S, Azam I, et al. Patient delay in breast cancer diagnosis in two hospitals in Karachi, Pakistan: preventive and life-saving measures needed. JCO Glob Oncol. 2020;6:873-883. doi:10.1200/GO.20.00034

17. Sarwar MR, Saqib A. Cancer prevalence, incidence and mortality rates in Pakistan in 2012. Cogent Med. 2017;4(1):1288773. doi:10.1080/2331205X.2017.1288773

18. Banning M, Hafeez H, Faisal S, Hassan M, Zafar A. The impact of culture and sociological and psychological issues on Muslim patients with breast cancer in Pakistan. Cancer Nurs. 2009;32(4):317-324. doi:10.1097/NCC.0b013e31819b240f

19. Soomro R, Faridi S, Khurshaidi N, Zahid N, Mamshad I. Age and stage of breast cancer in Pakistan: an experience at a tertiary care center. J Pak Med Assoc. 2018;68(11):1682-1685.

20. Gulzar F, Akhtar MS, Sadiq R, Bashir S, Jamil S, Baig SM. Identifying the reasons for delayed presentation of Pakistani breast cancer patients at a tertiary care hospital. Cancer Manag Res. 2019;11:1087. doi:10.2147/CMAR.S180388

21. Khan MA, Hanif S, Iqbal S, Shahzad MF, Shafique S, Khan MT. Presentation delay in breast cancer patients and its association with sociodemographic factors in North Pakistan. Chin J Cancer Res. 2015;27(3):288.
22. Pace LE, Mpunga T, Hategekimana V, et al. Delays in breast cancer presentation and diagnosis at two rural cancer referral centers in Rwanda. Oncologist. 2015;20(7):780. doi:10.1634/theoncologist.2014-0493

23. Salih AM, Alfaki MM, Alam-Elhuda DM, Nouradyem MM. Factors delaying presentation of Sudanese breast cancer patients: an analysis using Andersen's Model. Asian Pac J Cancer Prev. 2016;17 (4):2105-2110. doi:10.7314/APJCP.2016.17.4.2105

24. Ginsburg O. Breast and cervical cancer control in low and middle-income countries: human rights meet sound health policy. J Cancer Policy. 2013;1(3-4):e35-e41. doi:10.1016/j.jcpo.2013.07.002

25. Globocan. Globocan Pakistan Fact Sheet; 2019. Available from: $\mathrm{http} / /$ gco.iarc.fr/today/data/factsheets/populations/586-pakistan-factsheets.pdf. Accessed March 7.

26. Ashraf MS, Jamil A. Cancer Care in Pakistan. Cancer Care in Countries and Societies in Transition. Springer; 2016:231-245.

27. Banning M, Tanzeem T. Managing the illness experience of women with advanced breast cancer: hopes and fears of cancer-related insecurity. Eur J Cancer Care (Engl). 2013;22(2):253-260. doi:10.1111/ecc.12026

28. Hanif M, Sabeen B, Maqbool A, Ahmed A, Nadeem F, Habib S. Breast cancer: incidence (Thirteen year data analysis) and one year clinicopathological data of patients in a tertiary care cancer hospital. Int J Biol Biotechnol. 2015;12(3):373-379.
Cancer Management and Research

\section{Publish your work in this journal}

Cancer Management and Research is an international, peer-reviewed open access journal focusing on cancer research and the optimal use of preventative and integrated treatment interventions to achieve improved outcomes, enhanced survival and quality of life for the cancer patient.

\section{Dovepress}

The manuscript management system is completely online and includes a very quick and fair peer-review system, which is all easy to use. Visit http://www.dovepress.com/testimonials.php to read real quotes from published authors. 